\title{
THE SURFACE PHOTOCHEMISTRY OF PROCYMIDONE IN PRESENCE OF AMMONIUM FERRIC CITRATE
}

\author{
Ivan Osipov \\ Institute of Chemistry of Academy of Sciences of Moldova, 3, Academiei str., Chisinau MD-2028, Republic of Moldova \\ e-mail: osipov_i@yahoo.com; phone: (+373) 69245899
}

\begin{abstract}
The knowledge of the behaviour and fate of pesticides after their application is very important from the environmental, human health and economical points of view. The problem of pesticide residues on fruits is of major concern. Procymidone was chosen as the model compound and its phototransformation was followed under sunlight irradiation. The main photodegradation products on silica are: 3,5-dichloroaniline and 3,5-dichlorophenyl isocyanate.
\end{abstract}

The use of ammonium ferric citrate can enhance the degradation of procymidone.

Keywords: procymidone, ammonium ferric citrate, silica, phototransformation.

Received: September 2015/ Revised final: October 2015/ Accepted: October 2015

\section{Introduction}

Natural solid-gas interfaces, such as soil and vegetation, can accumulate some globally relevant pollutants, such as Persistent Organic Pollutants (POPs) and chemicals coming from chemical spills or resulting from applications with a specific purpose. Surfaces are, in most cases, the first contaminated environmental compartment and from which the generalized spread of organic pollutants takes place. A particular case is that of pesticide applications. They are needed to actuate on the surfaces during a certain period of time, but after this they become unwanted compounds and their residues should be removed. Photodegradation is recognized to be one of the major dissipation pathways of pesticides on solid surfaces under natural conditions [1]. Due to high agriculture impact and necessity of treatment in harvest close period, especially for wine production area, we have chosen procymidone as a model fungicide. The diffuse reflectance ground state absorption spectra of procymidone on silica showed the expected absorption band between 250 and $290 \mathrm{~nm}$ (see Figure 1). Under natural conditions, only the solar radiation above $290 \mathrm{~nm}$ arrives to the earth surface. Low overlap with the absorption of procymidone on silica occurs and therefore low direct photodegradation rates are expected under solar irradiation. Presence of additives, like ammonium ferric citrate, allows us to increase the photodegradation pathway by absorption of sunlight irradiation above $300 \mathrm{~nm}$. From the ground state absorbance of impregnated on silica procymidone with addition of ammonium ferric citrate as photosensitizer under sunlight irradiation (Figure 1), one can conclude, that the indirect phototransformation represents the main photodegradation pathway.

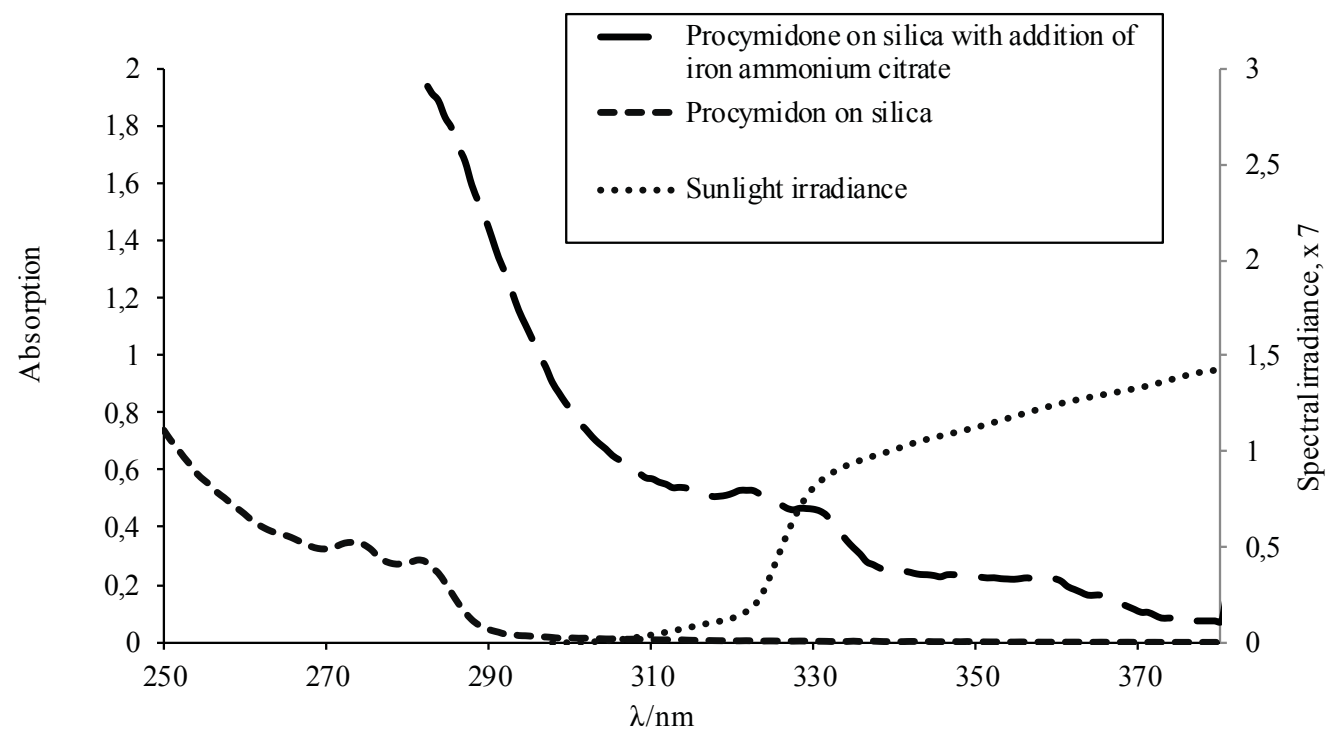

Figure 1. Normalized ground-state absorption spectra registered for impregnated on silica procymidon. 
In this field, advanced oxidation processes (AOPs) represent an important potential [3]. Iron aqua complexes are involved in formation of hydroxyl radical species via electron processes from excitation into ligand to metal charge transfer band [4]. Ammonium ferric citrate was used due to good iron solubilisation in the Fenton and photo-Fenton processes. Ammonium ferric citrate can be used at $\mathrm{pH}$ values up to 9.0 [5], therefore field experiments in neutral $\mathrm{pH}$ can also be performed. In order to gain more insights into the process of procymidone phototransformation in the presence of ammonium ferric citrate, it is important to compare photoproducts of the impregnated on silica procymidone with its photodegradation producs obtained after addition of ammonium ferric citrate. The acceleration of phototransformation of procymidone in the presence of ammonium ferric citrate is expected to take place.

\section{Materials and methods Materials}

Ammonium ferric citrate (Aldrich); Procymidon (Fluka); cellulose DSO (Fluka); silica (60 A) (Merck); methanol, ethanol, acetonitrile (Merck Lichrosolv) were used without further treatment. Water was distilled and deionized.

\section{Sample preparation}

Samples of impregnated on silica procymidone were initially prepared by using the solvent evaporation method. The final concentration of procymidone was determined by extracting the samples with methanol (a known weight of sample in a known volume of solvent), followed by centrifugation and HPLC analysis. All samples (10, 20, 50,100 and $400 \mathrm{mg} / 100 \mathrm{~g}$ silica) were prepared by mechanical mixture. To the correspondent amount of solid support the prepared samples were added, followed by magnetic stirring during 3 days. The final concentration of procymidone was determined by using HPLC.

\section{Irradiation conditions}

Photolysis studies were conducted in a system previously used to study pesticides and 4-chlorophenol [6]. The $254 \mathrm{~nm}$ radiation was obtained using a $16 \mathrm{~W}$ low-pressure mercury lamp (Applied Photophysics) without filters and without refrigeration. The photodegradation kinetics and product formation studies, under lamp and sunlight irradiation, were made by using samples prepared by spreading the solid powder on glass microscope slides ( $50 \mathrm{mg}$ spread on $\sim 10 \mathrm{~cm}^{2}$ ) covered with quartz slides. The edges of the slides were then sealed with parafilm to prevent the losses by volatilization. The samples used for the volatilization studies were prepared in the same way, but were kept opened (without the cover slide) in the dark. All the experiments were repeated three times.

The sunlight irradiation studies were performed in Algarve (South Portugal, latitude: $37^{\circ} \mathrm{N}$, longitude: $8^{\circ} \mathrm{W}$ ) in July and August. After irradiation procymidone residue and its photoproducts were extracted with methanol. The solar radiation was monitored using an International Light IL 700 A Research Radiometer, equipped with a SEE240 \#3358 detector, a W \# 6237 diffuser and a UVB \#12813 filter.

\section{Diffuse reflectance ground state absorption spectra}

Ground state absorption spectra of the solid powdered samples were recorded using a Cintra 40 GCB Scientific Equipment spectrophotometer, with a diffuse reflectance attachment. The measured reflectance was used to calculate the remission function using the Kubelka-Munk equation.

\section{Results and discussion}

In order to determine concentration of procymidone all samples were first analyzed by HPLC. Figure 2 presents the GS-MS traces of the impregnated on silica procymidone after $5 \mathrm{hrs}$ of sunlight irradiation with addition of ammonium ferric citrate and without additive. Samples were extracted with ethanol (ammonium ferric citrate is insoluble in ethanol).

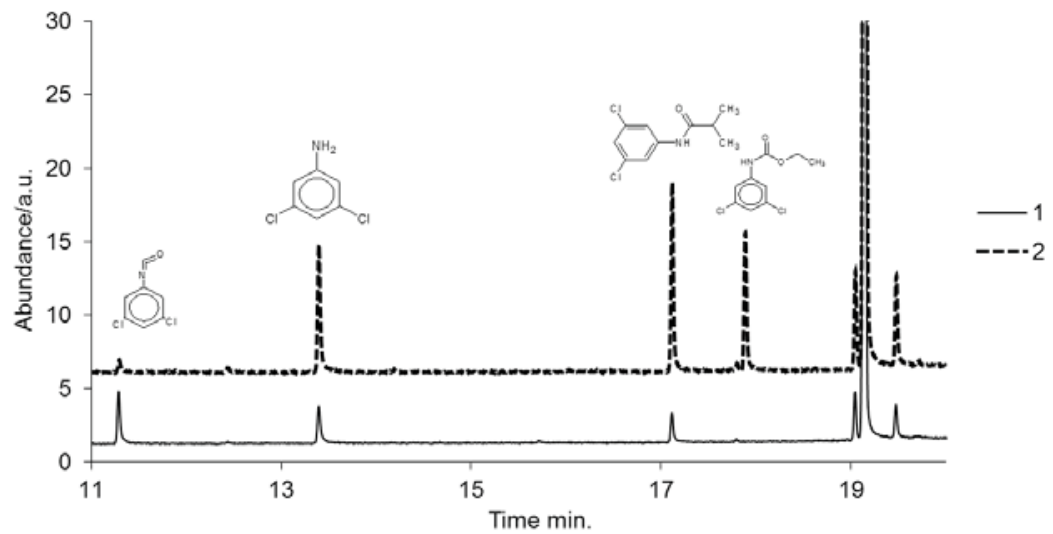

Figure 2. Normalized GS-MS traces of procymidone after 5 hrs of sunlight irradiation without additive (1) and with addition of ammonium ferric citrate (2). 
The main photoproducts of indirect phototransformation of procymidone in the presence of ammonium ferric citrate as photosensitizer on silica are: 3,5-dichlorophenyl isocyanate, 3,5-dicloroaniline and N-(3,5-dichlorophenyl)2-methylpropanamide. The degradation photoproducts of procymidone in the presence of ammonium ferric citrate are identical to the products of its phototransformation without additives. A product with retention time of 18 min is formed in reaction of 3,5-dichlorophenil isocyanate with ethanol, which was used for extraction. We have established that in the samples with addition of ammonium ferric citrate, after 5 hours of sunlight irradiation $75 \%$ of procymidone remained unchanged, in comparison with the samples, which were placed in the same conditions, but without photosensitizer.

\section{Conclusions}

In the course of our investigations it was shown, that by using ammonium ferric citrate as photosensitizer the indirect phototransformation of impregnated on silica procymidone under sunlight irradiation at neutral $\mathrm{pH}$ increased up to $25 \%$ decay in 5 hours. The obtained in these conditions phototransformation products are identical to those formed via natural partway.

\section{Acknowledgments}

I would like to acknowledge and express my sincere gratitude to my scientific adviser Acad. Gheorghe Duca for continuous guidance and encouragement throughout every process of my research. Also I would like to thank Dr. José Paulo Da Silva, for his valuable and constructive suggestions during planning and development of this research work.

\section{References}

1. Leifer, A. The Kinetics of Environmental Aquatic Photochemistry. ACS Professional Reference Book: Washington, $1988,336 \mathrm{p}$.

2. Da Silva, J.P.; Vieira Ferreira, L.F.; Oliveira, A.S. Photochemistry of 4-chlorophenol on cellulose and silica. Environmental Science \& Technology, 2003, 37, pp. 4798-4803.

3. Legrini, O.; Oliveros, E.; Braun, A. M. Photochemical processes for water treatment. Chemical Reviews, 1993, 49, pp. 671-698.

4. Brand, N.; Mailhot, G.; Bolte, M. Degradation photoinduced by Fe(III): method of alkylphenolethoxylates removal in water. Environmental Science \& Technology, 1998, 32, pp. 2715-2720.

5. Zepp R.G.; Faust, B.C.; Hoigne, J. Hydroxyl radical formation in aqueous reactions (pH 3-8) of iron(II) with hydrogen peroxide: the photo-Fenton reaction. Environmental Science \& Technology, 1992, 26, pp. 313-319.

6. Da Silva, J.P.; Vieira Ferreira, L.F.; Osipov, I.; Machado, I.F. Surface photochemistry of pesticides containing 4-chlorophenoxyl chromophore. Journal of Hazardous Materials, 2010, 179, pp. 187-191. 